\title{
Analysis of Homogeneity and Young's Moduli of Rubber Compounds by Atomic Force Microscopy
}

\author{
Dana Bakošová (0000-0003-2936-8637), Alžbeta Bakošová (0000-0003-3440-0689) \\ Faculty of Industrial Technologies in Púchov, Alexander Dubček University of Trenčín. I. Krasku 491/30, 020 \\ 01 Púchov. Slovakia.E-mail: dana.bakosova@tnuni.sk, alzbeta.bakosova@student.tnuni.sk
}

The atomic force microscopy is method used to obtain surface properties of various materials, including surface morphology, local magnetization, conductivity and mechanical properties. In this work the atomic force microscope was used to investigate properties of rubber compounds. Three samples made of different rubber compounds that varied in filler content were studied in order to determinate their homogeneity and ratios of their Young's moduli. Images of their surface topography were obtained and then on each sample five places were chosen where spectroscopic curves representing force - distance dependence were scanned. Parts of these curves from which Young's modulus can be determined were approximated by linear functions and their slope was calculated. Slope values close to each other suggest similar values of Young's modulus. By their comparison it was determined whether even distribution of ingredients in rubber compound can be assumed and thus the blending process to produce these compounds can be considered sufficient.

Keywords: Rubber compound, Atomic force microscopy, Spectroscopic curve, Sneddon's model, Young's modulus

\section{Introduction}

Scanning probe microscopy (SPM) has found application in various fields. These experimental devices are used to examine the microstructures of organisms, bacteria, viruses, but also the microstructure of materials such as metals, plastics and ceramics. The atomic force microscopy is method of great importance within the field of SPM. The atomic force microscope (AFM) is a device used mainly for investigation of the surface properties of samples. This method allows determining the local properties of the examined samples, such as surface morphology, local magnetization, reflectance and light absorption, electrical and thermal capacity, conductivity, etc. and can be used for wide range of materials [1].

Since invention of the AFM in 1986 by G. Binnig, C. Gerber and C. Quate a considerable number of scientific works that deal with use of the AFM for investigation of properties of polymers was published. Advantage of the AFM is its use to measure a wide range of material properties in addition to providing a surface image. It can be operated in various conditions including vacuum, air and liquid media and different range of temperatures. Commonly used modes to probe polymers are amplitude-modulation (tapping mode), force modes and electrical modes. There was also development in new imaging modes that expanded the special and temporal resolution of the AFM, such as infrared spectroscopy [2], multifrequency imaging [3] and high speed scanning [4].
Force-distance curve based imaging is a widely used approach in which the AFM tip scans over specified area of the specimen surface and corresponding force and tip displacement are recorded. Then these images can be translated into an area mapping of the surface properties (e. g. elastic modulus, adhesion, stiffness) by using appropriate contact mechanics models such as the Hertz, Derjaguin-Muller-Toropov and Johnson-Kendall-Roberts models [5].

In the study [6] nonlinear force-indentation equation based on the Mooney-Rivlin model is derived and used to fit data from the indentation of lightly crosslinked poly(vinyl alcohol) gels in equilibrium with water. This method showed good agreement with values of Young's modulus obtained by both macroscopic compression testing and by fitting of the force curves with the Hertz equation. Studies [7]-[9] examined elastic properties and estimated Young's modulus of different polymer materials. In [10] the AFM was used to study distribution of filler in a matrix and structural parameters for several EPDM-rubbers filled with carbon black N330, silicas Aerosil 200 and Aerosil R974 and with filler fractions 20 and $40 \mathrm{phr}$. The study [11] deals with nanoscale visualization and multiscale mechanical implications of bound rubber interphases in hydrogenated nitrile butadiene rubber with carbon black filler. Other studies in which the AFM was used to evaluate rubber micro-morphology include [12][15]. Authors in [16] examined structure of $\mathrm{SiO} 2 / \mathrm{rub}-$ ber nanocomposites. In [17], [18] and [19] authors focused on investigation of viscoelastic properties of 
various polymers using the AFM. Authors in [20] used the AFM for studying surface glass-to-rubber transition of poly(tert-butyl acrylate). In [21] AFM was used to study influence of the fillers on mechanical properties of polyamide. The paper [22] used the AFM to study laser surface modification of polystyrene and polyethylene naphthalate foils. More detailed state-ofart review of advances in use of the AFM in polymer investigation was carried out by Wang et al. in [23].

In this work the AFM was used to obtain surface morphology of samples made of three different rubber compounds and then to scan spectroscopic curves that show dependence of force between the probe and the sample surface on distance between them, which represents approaching and retracting of the probe. On each sample five places for scanning were chosen to obtain the spectroscopic curves, based on which the homogeneity and ratio of Young's modulus of the samples were evaluated. Homogeneity of the rubber compound is important in terms of its uniform mechanical properties and even distribution of fillers and curing agents is one of the governing factors determining these properties.

\section{Material}

Tab. and composition of the rubber compounds included:

- natural rubber (NR),

- butadiene rubber (BR),

- styrene-butadiene rubber (SBR 1500),

- vulcanizing agent - sulphur,

- sulfenamide vulcanization accelerator-CBS,
Rubber compound is mixture of natural and synthetic rubbers with many other additives, which affect its processability, allow vulcanization and determine properties of vulcanite. Rubber compounds are widely used in different fields and its composition depends mainly on the application of final products [24].

In this work the samples made of three different rubber compounds were measured and evaluated. The examined rubber compounds contained natural rubber (NR), butadiene rubber (BR) styrene-butadiene rubber (SBR 1500). The natural rubber is frequently used in rubber industry as it combines high strength with good resistance to fatigue. However, one of its drawbacks is low heat resistance, therefore it is often used in combination with synthetic rubbers to improve its temperature resistance. Synthetic rubber SBR-1500 is a styrene $(23.5 \%)$ and butadiene $(76.5 \%)$ copolymer. It is a general-purpose cold SBR with higher physicals and abrasion resistance than hot polymerized equivalents and it is suitable for products which do not require resistance to staining and discoloration. Synthetic rubber BR is widely used in tire treads and is noted for its low heat build-up, high resistance to abrasion and resistance to cracking [25].

The filler content in the examined rubber compounds is listed in the

- oil softener,

- silica filler ULTRASIL,

- carbon black filler,

- vulcanization activator - $\mathrm{ZnO}$,

- antidegradant DUSANTOX,

- antidegradant, antioxidant FLECTOL,

- vulcanization activator - STEARIN.

Tab. 1 Filler content (of the total compound volume)

\begin{tabular}{|c|c|c|c|}
\hline & Compound 1 & Compound 2 & Compound 3 \\
\hline Carbon black content $(\%)$ & 5.0 & 12 & 30 \\
\hline Silica filler content $(\%)$ & 35.0 & 20 & 5 \\
\hline
\end{tabular}

The blending process of rubber compounds consisted of two stages. All the mentioned types of rubbers, fillers and other additives were added at the first stage, except for the sulphur vulcanizing agents and CBS, which were added in the second stage. The blending procedures consisted of several steps, with each step having a specified temperature, time and machine speed. First, the rubbers entered the blending machine according to the recipe and were mixed. Next, chemicals and part of the fillers followed. Then, an oil softener was added which reduced the viscosity of the mixture along with the rest of the fillers. Then the blend was mixed, dusted, mixed again and discharged. For the second stage, the blend was prepared by rolling on a twin roll machine in order to achieve a better dispersion of the particles in the blend. After rolling, the blend was cut into smaller pieces in the form of strips. In the second blending step, the blend was mixed at a temperature of up to $105^{\circ} \mathrm{C}$ for $150 \mathrm{~s}$, while vulcanizing chemicals according to the recipe were added.

\section{Methods}

The AFM uses a sharp several micrometres long tip, to scan the surface of the sample, the tip is attached at the free end of the cantilever, that is used to sense the interaction forces between the tip and the sample surface. By using a piezoelectric crystal, the cantilever with the tip rasterize in the $x-y$ plane parallel to the sample surface. The sharp tip copies relief on the sample surface and bends in the $z$-axis direction 
perpendicular to the sample surface. Bending detection is based on the optical principle. The beam from the laser diode is reflected from the end of the cantilever to the photodetector. During the measurement, the bending of the cantilever is manifested by the displacement of the trace of the reflected beam, so that the energy of beam falling on the individual parts of the detector will not be the same and from their ratio it is possible to determine the deflection of the cantilever. It is also possible to detect the deflection in the horizontal direction (lateral force microscopy). The deflection of the beam is recorded during the measurement and the resulting surface topography is generated by further software processing [26].

The tip, which is in close proximity to the surface, is subjected in particular to short-range repulsive forces of electrostatic origin and long-range attractive Van der Waals forces. Precise quantum-mechanical calculation of these forces acting between the tip and the surface atoms is relatively complex. The influence of both forces can be modelled, for example, by the empirical Lennard - Jones potential [5].

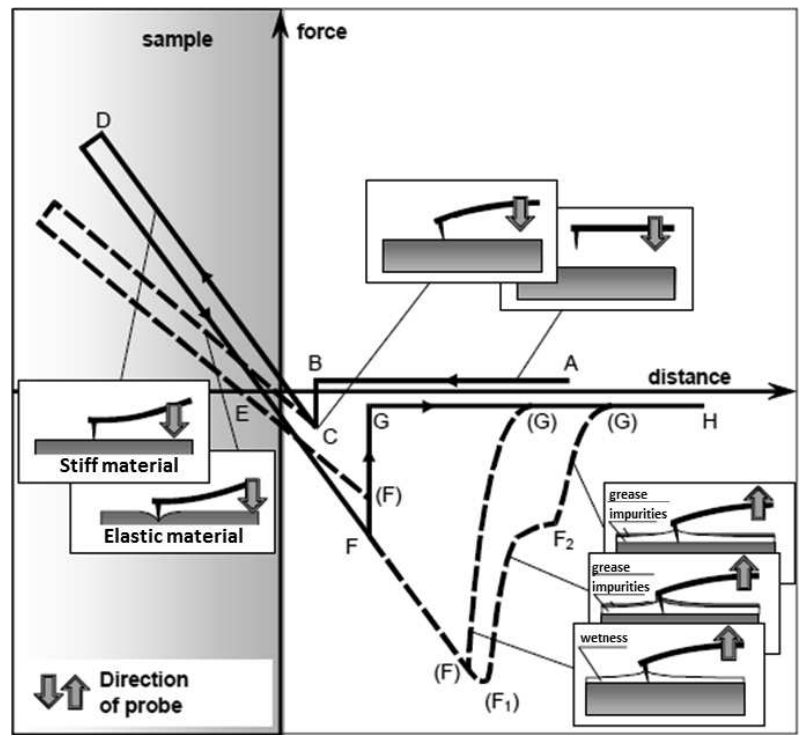

Fig. 1 Force-distance curves representing the probe approaching and retracting the sample [28]

Using the AFM, it is possible to capture curves showing the dependence of the interaction force between probe and the sample surface on the distance between them during approaching and retracting of the probe. These curves are important for measuring the vertical force applied to the surface by the tip in the scanning process. Parameters that can be evaluated based on the curves also include the viscosity of the surface impurities, the thickness of the coating layer and the local variations of the elastic properties of the surface. The approaching/retracting curve is influenced by thin layers of moisture, which are normally present when working with the AFM in the air environment, as well as smudges and impurities.
Curves are specific for each sample, however they can be divided in general characteristic sections as shown in Fig. [27].

Section A - B: probe is completely moved off, the tip is not in the contact with the sample and the cantilever is not bent. During approaching the cantilever bends when the Van der Waals forces start to act in the point $\mathrm{B}$.

Section B - C: the cantilever suddenly begins to move towards the sample surface and in the point $\mathrm{C}$ the tip begins to be in a contact with the surface. In addition to electrostatic forces and Van der Waals attractive forces, the shape of the curve is influenced by the surface moisture and impurities. Force value change in the section $\mathrm{B}-\mathrm{C}$ can be related to the shrinkage of the tip characterized by the Hook law ( $F$ $=-k . \Delta x)$ and it allows to identify the thickness of absorbent layer on the sample surface.

Section C-D: the probe further approaches the sample which is accompanied by pressing of the tip to the surface and almost linear rise of force value. From this part of the curve Young's modulus of the probe surface system can be evaluated. In the case of the much softer measuring probe compared to the sample surface the slope of the curve presents mostly elastic constant of the cantilever itself. Contrariwise, if the sample is much more elastic the slope of the curve allows studying elastic features of the sample. However, the section $\mathrm{C}-\mathrm{D}$ does not have to be straight line and in this case the change of the slope shows differences in surface reactions to force applied by the tip.

Section D-E: in the point D the approaching phase ends and the retracting phase from the surface starts. If hysteresis of the scanning device is not presents, this section is basically the same as the approaching section $\mathrm{C}-\mathrm{D}$. If both sections are straight and parallel they do not provide any additional information. In the case when they are not parallel it is possible to determine plastic and elastic deformation of the sample provided the surface geometrical features recover at slower rate than the probe retracts.

Section E-F: the point E refers to the neutral deflection of the cantilever and when the probe further retracts from the surface, the cantilever starts to incline towards the sample as the tip is affected by adhesive force. The presence of absorbing layers on the sample surface influences the shape of this section. In the vacuum, Van der Waals and electrostatic forces affect the tip. However, in air environment quite strong capillary force of moisture of the surface layer is added to these forces and the final force value is also affected by impurities. The length of the section $\mathrm{E}-\mathrm{F}$ and its inclination are influenced by the thickness of the surface layers. Probe separates from the sample surface, when the elastic response of the cantilever outruns attractive force of the surface and its layers, which is represented by the point $\mathrm{F}$. 
Section F - G: The size of load in the point of separation $\mathrm{F}$ is equal to the total maximum adhesive force between sample surface and the probe and gives information about adhesion. If the moisture layer is covered with layer of grease or other impurities, more than one point of separation can be observed (points $F_{1}$ and $F_{2}$ ). Viscosity and thickness of these layers alter position of the points $F_{1}$ and $F_{2}$. Transition between the sections $\mathrm{E}-\mathrm{F}$ and $\mathrm{F}-\mathrm{G}$ does not necessarily increase steeply. If viscosity of absorbing layer is big enough, the probe can retract from the sample surface gradually and the shape of this transition is round [27], [28], [29].

\subsection{Snedonn's model}

General approximation and Snedonn's model was used to analyse measured data and to calculate the ratios of the Young's moduli [5], [30]. Snedonn's model gives the dependence between the load gradient $d P / d h$ and the Young's modulus $E$ given by the equation (1):

$$
\frac{d P}{d h}=\frac{2 A^{1 / 2}}{\pi^{1 / 2}} E\left[\mathrm{Nm}^{-1}\right]
$$

where $E$ is a combined modulus of elasticity of examined material and the probe given by the equation (2): $E=\left\{\left[\left(1-v_{m}^{2}\right) / E_{m}\right]+\left[\left(1-v_{c}^{2}\right) / E_{c}\right]\right\}^{-1}[P a],(2)$ where $E_{m}, E_{c}[\mathrm{~Pa}]$ are Young's moduli of the sample and the cantilever, respectively, $\nu_{m}, \nu_{c}[-]$ are Poisson ratios of the sample and cantilever, $P[\mathrm{~N}]$ is normal load, $A\left[\mathrm{~mm}^{2}\right]$ is contact area and $h[\mathrm{~m}]$ is indentation depth. It can be assumed $E_{c} \gg E_{m}$, therefore $E_{m}=E[5]$. The following equations represent the moduli of two different samples:

Tab. . It has following operation modes:

- Static (including contact mode and lateral force microscopy),

$$
\begin{aligned}
& \frac{d P_{1}}{d h_{1}}=\frac{2 A^{1 / 2}}{\pi^{1 / 2}} E_{1} \Rightarrow E_{1}=\frac{d P_{1}}{d h_{1}} \frac{\pi^{1 / 2}}{2 A^{1 / 2}}, \\
& \frac{d P_{2}}{d h_{2}}=\frac{2 A^{1 / 2}}{\pi^{1 / 2}} E_{2} \Rightarrow E_{2}=\frac{d P_{2}}{d h_{2}} \frac{\pi^{1 / 2}}{2 A^{1 / 2}},
\end{aligned}
$$

and their ratio can be formulated as:

$$
\frac{E_{1}}{E_{2}}=\frac{\frac{d P_{1}}{d h_{1}} \frac{\pi^{1 / 2}}{2 A^{1 / 2}}}{\frac{d P_{2}}{d h_{2}} \frac{\pi^{1 / 2}}{2 A^{1 / 2}}} \Rightarrow \frac{E_{1}}{E_{2}}=\frac{\frac{d P_{1}}{d h_{1}}}{\frac{d P_{2}}{d h_{2}}} .
$$

The part of the curve from which the tensile modulus can be determined was approximated by linear function in order to find the slope $k$. Considering the formulas (5) to (7) the equation (8) can be derived, which was used to obtain ratio of Young's moduli of the samples 1 and 2 . Similarly relation between Young's moduli of the samples 1 and 3 can be formulated.

$$
\begin{gathered}
y=k x+q, \text { where } k=\frac{d P}{d h}, \\
\frac{d P_{1}}{d h_{1}}=k_{1} \text { and } \frac{d P_{2}}{d h_{2}}=k_{2}, \\
\Rightarrow \frac{E_{1}}{E_{2}}=\frac{k_{1}}{k_{2}} .
\end{gathered}
$$

\section{Experimental part}

Three samples made of different rubber compounds were examined. The aim was to evaluated their homogeneity in order to determinate even distribution of the fillers and thus to determine suitability of used blending process. For examination of tested samples the AFM NT- 206 was used and its technical specifications are listed in the

- Dynamic (including non-contact and intermittent mode),

- Static/Dynamic force spectroscopy.

Tab. 2 technical specifications of AFM NT- 206

\begin{tabular}{|l|l|}
\hline Scan rate & $10 \mu \mathrm{m} / \mathrm{s}$ \\
\hline Max. sample size & $30 \times 30 \times 8 \mathrm{~mm}$ \\
\hline Max. range of movement in the plane x-y & $10 \times 10 \mathrm{~mm}$ \\
\hline Max. scanning area & $20 \times 20 \times 3 \mu \mathrm{m}$ \\
\hline Power supply & $220 \mathrm{~V}, 50 \mathrm{~Hz}$ \\
\hline Operating environment & Air, $760 \pm 40 \mathrm{~mm} \mathrm{Hg}$ col., $22 \pm 4^{\circ} \mathrm{C}, \mathrm{RH}<70 \%$ \\
\hline Detection system & $\begin{array}{l}\text { Laser beam, four-quadrant position sensitive photode- } \\
\text { tector }\end{array}$ \\
\hline Scanner type & A piezoceramic tube \\
\hline Scanning unit dimension and weight & $185 \times 185 \times 290 \mathrm{~mm}, 4.7 \mathrm{~kg}$ \\
\hline Control electronic unit dimension and weight & $470 \times 210 \times 195 \mathrm{~mm}, 7.7 \mathrm{~kg}$ \\
\hline Scanning matrix & Up to $1024 \times 1024$ points \\
\hline
\end{tabular}

The AFM was used to obtain topography of the samples. Based on obtained topography on each sample five spots, that appeared heterogeneous, were chosen for which spectroscopic curve was scanned. The part of the curve from which the tensile modulus can be determined was approximated by linear function in order to find the slope $k$. Values of the slope were compared and the ratios of Young's moduli of individual compounds $E_{1} / E_{2}$ and $E_{1} / E_{3}$ were calculated. In the Fig. to Fig. the topography of the samples made of rubber compounds 1-3 and selected spots for scanning of spectroscopic curves are shown. 


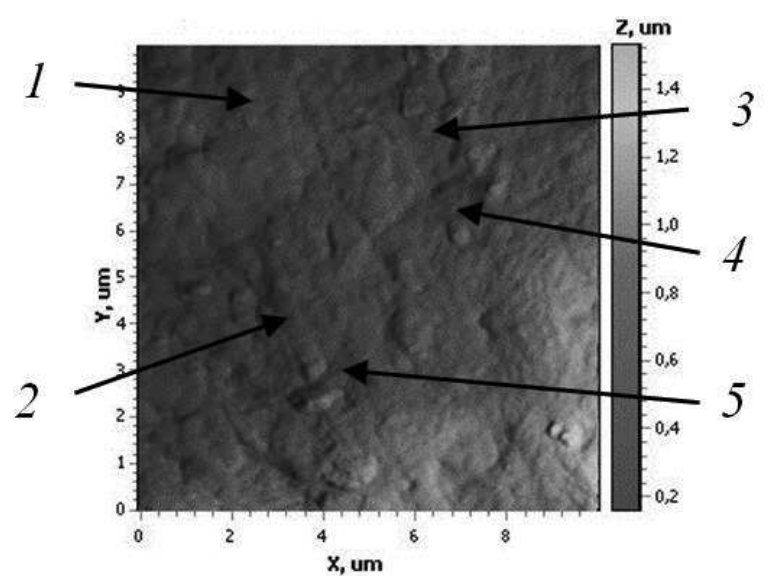

Fig. 2 The sample made of compound 1

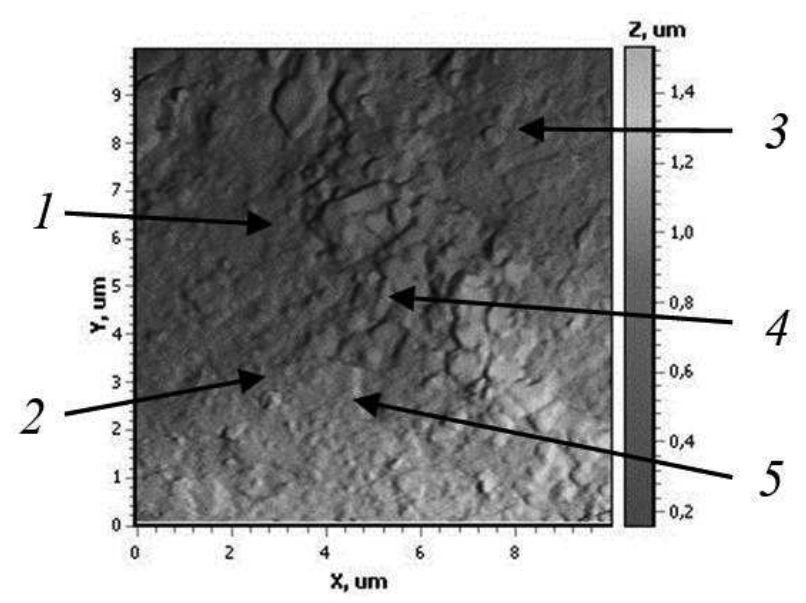

Fig. 3 The sample made of compound 2

The example of the spectroscopic curve is in the Fig. . This curve was scanned on the spot 1 on the

Tab. . From these average values ratios $E_{1} / E_{2}$ and $E_{1} / E_{3}$ were calculated and values of $E_{2}, E_{3}$ can be estimated as follows: sample 1 and approximation by linear function with slope $k_{1-1}=-1.6276$ can also be seen in the Fig. .

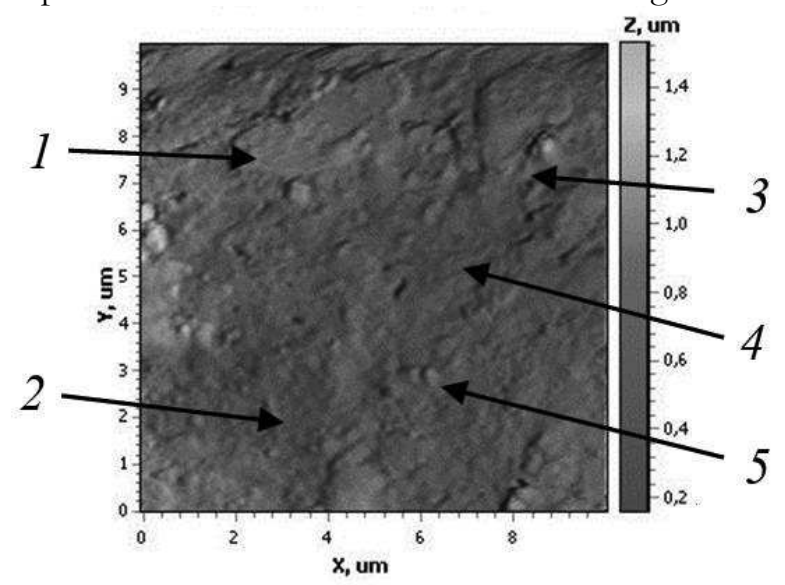

Fig. 4 The sample made of compound 3

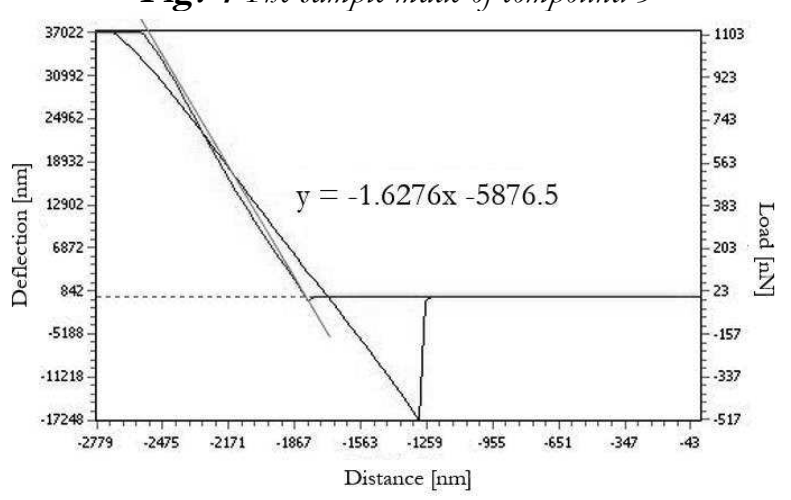

Fig. 5 Spectroscopic curve of the spot 1 on the sample 1

The slopes of each curve and average values $\mathrm{k}_{1}-\mathrm{k}_{3}$ for each sample are listed in the

$$
\begin{aligned}
& E_{2}=\frac{k_{2 E_{1}}}{k_{1}}=\frac{-1.4456}{-1.6249} E_{1}=0.8897 E_{1} \\
& E_{3}=\frac{k_{3 E_{1}}}{k_{1}}=\frac{-1.3241}{-1.6249} E_{1}=0.8149 E_{1}
\end{aligned}
$$

Tab. 3 Slope values of linear functions used to approximate spectroscopic curves

\begin{tabular}{|l|c|c|c|c|c|c|}
\hline Sample 1 & $\mathrm{k}_{1-1}$ & $\mathrm{k}_{1-2}$ & $\mathrm{k}_{1-3}$ & $\mathrm{k}_{1-4}$ & $\mathrm{k}_{1-5}$ & $\mathrm{k}_{1}$ \\
\hline Slope value & -1.6276 & -1.6224 & -1.6241 & -1.6238 & -1.6268 & -1.6249 \\
\hline Sample 2 & $\mathrm{k}_{2-1}$ & $\mathrm{k}_{2-2}$ & $\mathrm{k}_{2-3}$ & $\mathrm{k}_{2-4}$ & $\mathrm{k}_{2-5}$ & $\mathrm{k}_{2}$ \\
\hline Slope value & -1.4467 & -1.4431 & -1.4458 & -1.4487 & -1.4437 & -1.4456 \\
\hline Sample 3 & $\mathrm{k}_{3-1}$ & $\mathrm{k}_{3-2}$ & $\mathrm{k}_{3-3}$ & $\mathrm{k}_{3-4}$ & $\mathrm{k}_{3-5}$ & $\mathrm{k}_{3}$ \\
\hline Slope value & -1.3245 & -1.3254 & -1.3221 & -1.3258 & -1.3228 & -1.3241 \\
\hline
\end{tabular}

\section{Results and discussion}

The topography of the sample surfaces (Fig. -Fig. ) and spectroscopic curves for five spots on each sample were measured. The part of the curve, from which elastic properties can be obtained, was approximated by linear function as can be seen in the Fig. and the slope $k$ was calculated. Slope values for individual samples varied minimally, which suggest that meas- ured spots of the samples have similar elastic properties. Thus in combination with visual evaluation of the topographic pictures it can be assumed that sufficient homogeneity of each sample was obtained by the blending process. Other methods that can be used to evaluate homogeneity of rubber compound include measuring of electrical conductivity [24] and techniques using interferometric microscopy [31].

By comparison of the average slope values of the samples it can be noted that the sample made of the 
compound 1 has the highest value of Young's modulus and sample compound 3 the lowest. The values of Young's moduli for samples 2 and 3 can be expressed in reference to Young's modulus of the sample 1 as $E_{2}=0.8897 E_{1}$ and $E_{3}=0.8149 E_{1}$, respectively. The variation in the Young's modulus is caused by different content of carbon black and silica fillers in the rubber compounds.

\section{Conclusions}

The main task was to evaluate the homogeneity of the examined samples made of different rubber compounds using the AFM. The homogeneity of the mixture, which is important in terms of durability, quality and reliability of rubber products, is achieved by the blending process. Therefore, evaluation of the homogeneity is important factor in determination of sufficiency of the blending process. The samples were examined by the atomic force microscope and general approximation and Snedonn's model were used to analyse measured data. It was found that all three samples are homogeneous, as evidenced by the above topographic images and comparisons of the slope values of the spectroscopic curves approximated by linear function. Thus, blending process can be declared sufficient. From the average slope values of the individual samples ratios of their Young's moduli $E_{1} / E_{2}$ and $E_{1} / E_{3}$ were calculated and it can be concluded that the sample 1 has the highest value of Young's modulus and the sample 3 the lowest. This is due to the silica filler content as the higher percentage of silica contributes to higher stiffness and tensile strength. The calculation of Young's moduli ratios can be useful for estimation of modulus values for instances when larger number of samples is investigated, where Young's modulus of reference sample is known or measured by a tensile test.

\section{Acknowledgement}

This research work has been supported by the Operational Programme Integrated Infrastructure, co-financed by the European Regional Development Fund by the project: Advancement and support of $R \& D$ for "Centre for diagnostics and quality testing of materials" in the domains of the RIS3 SK specialization, Acronym: CEDITEK II., ITMS2014+ code 313011W442. This research work has been supported also by the Slovak Grant Agency KEGA 011TnUAD-4/2021.

\section{References}

[1] SCHÖNHERR, H., VANCSO, G. J. (2010). Scanning force microscopy of polymers. pp 4-
23. Springer, Heidelberg. ISBN 978-3-64201231-0.

[2] DAZZI, A., PRATER, C. B. (2017). AFM-IR: Technology and applications in nanoscale infrared spectroscopy and chemical imaging. In: Chemical reviews, Vol.117, No.7, pp. 5146-5173. ACS Publication. https://doi.org/10.1021/acs.chemrev.6b00448. ISSN 1520-6890.

[3] GARCIA, R., HERrUZO, E. T. (2012). The emergence of multifrequency force microscopy. In: Nature nanotechnology, Vol.7, No.4, pp. 217-226. DOI:10.1038/nnano.2012.38. ISSN 1748-3395.

[4] ANDO, T. (2012). High-speed atomic force microscopy coming of age. In: Nanotechnology, Vol. 23, No. 6. doi: 10.1088/09574484/23/6/062001. ISSN 0957-4484.

[5] TSUKRUK, V. V., et al. (1998). Probing of micromechanical properties of compliant polymeric materials. In: Journal of materials science, Vol. 33, No. 20, pp. 4905-4909. DOI:10.1023/A:1004457532183. ISSN 15734803.

[6] LIN, D. C., DIMITRIADIS, E. K., HORKAY, F. (2007). Elasticity of rubber-like materials measured by AFM nanoindentation. In: Express Polymer Letters, Vol. 1, No. 9, pp. 576-584. DOI: 10.3144/expresspolymlett.2007.79. ISSN 1788-618X.

[7] NUKAGA, H., et al. (2007). Evaluation of the Mechanical Properties of Carbon Black Reinforced Natural Rubber by Atomic Force Microscopy. In: International Polymer Science and Technology, Vol. 34, No. 4, pp. 49-56. https://doi.org/10.1177/0307174X070340041 1. ISSN 1478-2405.

[8] FERENCZ, R., et al. (2012). AFM nanoindentation to determine Young's modulus for different EPDM elastomers. In: Polymer Testing, Vol. 31, No.3, pp. 425-432. https://doi.org/10.1016/j.polymertesting.2012.01.003. ISSN 0142-9418.

[9] LONGO, M., et al. (2018) Force spectroscopy determination of Young's modulus in mixed matrix membranes. In: Polymer, Vol. 156, pp. 22-29. https://doi.org/10.1016/j.polymer.2018.09.043. ISSN 0032-3861.

[10] MOROZOV, I. A. (2011). A novel method of quantitative characterization of filled rubber structures by AFM. In: KGK Rubberpoint, Vol. 64, pp. 24-27. ISSN 9483276. 
[11] QU, M. et al. (2011) Nanoscale visualization and multiscale mechanical implications of bound rubber interphases in rubber-carbon black nanocomposites. In: Soft Matter, Vol. 7, No. 3, pp. 1066-1077. DOI:10.1039/COSM00645A. ISSN 1744-6848.

[12] SARKAWI, S. et al. (2013). Morphology of Silica-Reinforced Natural Rubber: Effect of Silane Coupling Agent. In: Rubber chemistry and technology. Vol. 88, pp. 359-372. DOI:10.5254/rct.15.86936. ISSN 0035-9475.

[13] YERINA, N., MAGONOV, S. (2003). Atomic force microscopy in analysis of rubber materials. In: Rubber chemistry and technology, Vol. 76, No. 4, pp. 846-859. https://doi.org/10.5254/1.3547776. ISSN 0035-9475.

[14] JEON, I. H., KIM, H., KIM, S. G. (2003). Characterization of rubber micro-morphology by atomic force microscopy (AFM). In: Rubber chemistry and technology, Vol. 76, No. 1, pp. 1-11. https://doi.org/10.5254/1.3547733. ISSN 0035-9475.

[15] WANG, C. C., et al. (2005). AFM study of rubber compounds. In: Rubber chemistry and technology, Vol. 78, No. 1, pp. 17-27. https://doi.org/10.5254/1.3547869. ISSN 0035-9475.

[16] TIAN, C., et al. (2019). Quantitatively identify and understand the interphase of $\mathrm{SiO} 2 /$ rubber nanocomposites by using nanomechanical mapping technique of AFM. In: Composites Science and Technology, Vol. 170, pp. 1-6. https://doi.org/10.1016/j.compscitech.2018.11.020. ISSN 0266-3538.

[17] TRANCHIDA, D., et al. (2009). Nanoscale mechanical characterization of polymers by atomic force microscopy (AFM) nanoindentations: viscoelastic characterization of a model material. In: Measurement Science and Technology, Vol. 20, No.9. https://doi.org/10.1021/ma052727j. ISSN 1361-6501.

[18] IGARASHI, T., et al. (2013). Nanorheological mapping of rubbers by atomic force microscopy. In: Macromolecules, Vol. 46, No. 5, pp. 1916-1922. DOI:10.1021/ma302616a. ISSN 1520-5835.

[19] MOELLER, G., (2009). AFM nanoindentation of viscoelastic materials with large end-radius probes. In: Journal of Polymer Science Part B: Polymer Physics, Vol. 47, No. 16, pp. 1573-1587. DOI:10.1002/polb.21758. ISSN 1099-0488.
[20] TSUI, O. et al. (2000). Studying surface glassto-rubber transition using atomic force microscopic adhesion measurements. In: Macromolecules, Vol. 33, No. 11, pp. 4198-4204. https://doi.org/10.1021/ma991473x. ISSN 1520-5835.

[21] BAKOŠOVÁ, D. (2018). Study of the Fillers Influence on Mechanical Properties of Polyamide by Using of AFM. In: Manufacturing Technology, Vol. 18, No. 2, pp. 173-178. DOI:10.21062/ujep/73.2018/a/12132489/MT/18/2/173. ISSN 1213 - 2489.

[22] ŠVORČÍK, V., et al. (2018). Construction and properties of ripples on polymers for sensor applications. In: Manufacturing Technology, Vol. 18 No.5, pp. 851-855. DOI: $10.21062 /$ ujep/189.2018/a/12132489/MT/18/5/851. ISSN 1213 - 2489.

[23] WANG, D., RUSSELL, T. P. (2018). Advances in atomic force microscopy for probing polymer structure and properties. In: Macromolecules, Vol. 51, No.1, pp. 3-24. https://doi.org/10.1021/acs.macromol.7b01459. ISSN 1520-5835.

[24] BAKOŠOVÁ, D. (2019). The study of the distribution of carbon black filler in rubber compounds by measuring the electrical conductivity. In: Manufacturing Technology, Vol. 19, No. 3, pp. $\quad 366-370$. DOI: 10.21062/ujep/297.2019/a/12132489/MT/19/3/366. ISSN 1213 - 2489.

[25] VAŠINA, M., PÖSCHL, M., ZÁDRAPA, P. (2021) Influence of rubber composition on mechanical properties. In: Manufacturing Technology, Vol. 21, No. 2, pp. 260-268. https://doi.org/10.21062/mft.2021.021. ISSN 1213 - 2489.

[26] WIESENDANGER, R., ROLAND, W. (1994). Scanning probe microscopy and spectroscopy: methods and applications. Cambridge university press. ISBN 0521428475

[27] WEISENHORN, A. L., et al. (1989) Forces in atomic force microscopy in air and water. In: Applied physics letters, Vol. 54, No. 26, pp. 26512653. https://doi.org/10.1063/1.101024. ISSN 1077-3118.

[28] СУСАОВ, А. А., ЧИЖИК, С. А. (1997) Сканирующие зондовые микроскопы (обзор). In: Материальг, технологии, инструменты, Vol.2, No. 3, pp. 78-89. ISSN 1607-9922. 
[29] HUTTER, J.L., BECHHOEFER, J. (1994).Measurement and manipulation of van der Waals forces in atomic-force microscopy. In: Journal of Vacuum Science \& Technology B: Microelectronics and Nanometer Structures Processing, Measurement, and Phenomena, Vol. 12, No. 3, pp. 2251-2253. https://doi.org/10.1116/1.587752. ISSN 2166-2754.

[30] SHULHA, H., et al. (2004). Some aspects of AFM nanomechanical probing of surface polymer films. In: European Polymer Journal, Vol.40,
No.5,

pp.

949-956.

https://doi.org/10.1016/j.eurpolymj.2004.01.021. ISSN 0014-3057.

[31] SMITH, A. P., et al. (2004). Carbon black dispersion measurement in rubber vulcanizates via interferometric microscopy. In: Rubber chemistry and technology, Vol. 77, No. 4, pp. 691-710. https://doi.org/10.5254/1.3547845. ISSN 0035-9475. 